\title{
Randomized Prospective Comparison of Glidescope Video Laryngoscope with Macintosh Laryngoscope in Adult who Underwent Thyroid or Parathyroid Surgery Using Neuromonitorization
}

\author{
(D) Murat Gunes, ${ }^{1}$ (I) Ayse Surhan Cinar, ${ }^{2}$ (D) Mehmet Uludag ${ }^{3}$ \\ 'Department of Anesthesiology Intensive Care Unit, Izmir Health Sciences University Tepecik Training and Research Hospital, Izmir, Turkey \\ ${ }^{2}$ Department of Anesthesiology and Reanimation, University of Health Sciences Turkey, Sisli Hamidiye Etfal Teaching and Resarch \\ Hospital, Istanbul, Turkey \\ ${ }^{3}$ Department of Anesthesiology and Reanimation, University of Health Sciences Turkey, Sisli Hamidiye Etfal Teaching and Resarch Hospital; \\ Department of General Surgery, University of Health Sciences Turkey, Sisli Hamidiye Etfal Teaching and Resarch Hospital, Istanbul, Turkey
}

\begin{abstract}
Objectives: The present study aims to compare the effects of Glidescope Video Laryngoscope (GVL) and Machintosh Laryngoscope (ML) on the hemodynamic response, intubation time and mucosal damage in adult patients who underwent thyroid or parathyroid surgery using neuromonitorization.

Methods: In this study, 180 patients, aged between 22 and 65 classified as Class I-II in ASA (American Society of Anesthesiologists) and operated under elective conditions were included. Patients were assigned into two groups: Patients intubated with GVL Group $G(n=90)$ and patients intubated with $M L$ Group $M(n=90)$. In both groups, intubation time and the number of trials were recorded. HR (Heart Rate), $\mathrm{SpO}_{2}$ (Peripheral Capillary Oxygen Saturation), SBP (Systolic Blood Pressure), DBP (Diastolic Blood Pressure) and MBP (Mean Blood Pressure) scores were recorded at preinduction, post-induction, post-intubation and three minutes after intubation. Post-operative intubation-associated complications were recorded.

Results: Post intubation HR, DBP and MBP scores were found to be significantly higher in Group M than Group G ( $p=0,006, p=0.013$, $p=0.011)$. Intubation time was found to be significantly higher in Group $G$ than in group $M(35.3 \pm 10.3,22.1 \pm 7.7 \mathrm{sec})$. There was no significant difference between the groups' number of trials and intubation-associated complications.

Conclusion: Despite its long intubation time, we believe that GVL may be the first choice laryngoscopy method in the thyroid or parathyroid cases that intubated with a low dose muscle relaxant for neuromonitoring since it has a slight effect than ML on hemodynamism it does not increase mucosal damage and has improved visibility.

Keywords: Glidescope video laryngoscope; macintosh laryngoscope; neuromonitorization; parathyroid surgery; thyroid surgery.

Please cite this article as "Gunes M, Surhan Cinar A, Uludag M. Randomized Prospective Comparison of Glidescope Video Laryngoscope with Macintosh Laryngoscope in Adult who Underwent Thyroid or Parathyroid Surgery Using Neuromonitorization. Med Bull Sisli Etfal Hosp 2020;54(3):320-326".
\end{abstract}

Etub dotracheal intubation is the procedure of placing a tube in the trachea to ensure the patient's airway safety and control inhalation. During intubation and recurrent tri-

als, physiopathological changes, such as mucosal damage, tachycardia, increase in blood pressure, intracranial pressure and intraocular pressure, may occur. ${ }^{[1]}$ Video laryngos-

Address for correspondence: Murat Gunes, MD. Izmir Saglik Bilimleri Universitesi Tepecik Egitim ve Arastirma Hastanesi Anesteziyoloji Yogun Bakim Unitesi, Izmir, Turkey

Phone: +90 5367855184 E-mail: muratgunes_294@hotmail.com

Submitted Date: June 23, 2020 Accepted Date: June 30, 2020 Available Online Date: September 14, 2020

${ }^{\circ}$ Copyright 2020 by The Medical Bulletin of Sisli Etfal Hospital - Available online at www.sislietfaltip.org

OPEN ACCESS This is an open access article under the CC BY-NC license (http://creativecommons.org/licenses/by-nc/4.0/). 
copy for tracheal intubation is one of the newest developments. Contrary to conventional laryngoscopy, where anesthesiologists have a narrower view of airway structures while advancing the tracheal tube, an enlarged view of the airway is obtained with video laryngoscopy. ${ }^{[2]}$ In thyroid or parathyroid surgery, neuromonitoring tube mostly used to prevent RLS (Recurrent Laryngeal Nerve) injury. In addition, proper tube position is the most effective technical feature to perform effective neuromonitoring. ${ }^{[3]}$ In the application of the neuromonitoring tube, all drugs that block neuromuscular activity during the operation should be avoided. ${ }^{[4]}$ It is recommended to use low-dose muscle relaxant at the start of surgery to ensure adequate muscle relaxation during intubation without significantly affecting the evoked potentials measured by neuromonitoring. ${ }^{[5,6]}$ We wondered how low-dose muscle relaxant using would affect patients' hemodynamics during intubation in different intubation techniques. In this study, the aim was to compare the effects of Glidescope Video Laryngoscope (GVL) and Macintoch Laryngoscope (ML) on hemodynamics response, intubation time and mucosal damage in patients who underwent thyroid and parathyroid surgery under elective conditions by using neuromonitorization.

\section{Methods}

Our study was carried out in Sisli Hamidiye Etfal Teaching and Resarch Hospital Hospital (700 beds) with 180 volunteers who signed "Informing Volunteers and Consent Form" and underwent thyroid or parathyroid surgery under elective conditions between March and September 2017. This study was designed to be randomized and prospective. No. 71146310-511.06-E.212131 Ministry of Health, Turkey Pharmaceuticals and Medical Devices Agency received ethics committee approval. Age range 22- 65 years and patients ASA (American Society of Anesthesiologists) I-II group were included in this study. Patients with a history of allergy, ASA 3 and above, mouth-nose-face deformity, mass in the oropharynx and who were operated for secondary thyroid cancer were excluded from this study.

Age, gender, height, weight, type of surgery and ASA grades of the patients were recorded before surgery. Randomization was performed with a sealed opaque envelope system. Patients were assigned into two groups: patients intubated with GVL Group $\mathrm{G}(\mathrm{n}=90)$ and patients intubated with $\mathrm{ML}$ Group M ( $n=90)$ Modified Mallampati Scores were evaluated and were scored from 1 to 4 and recorded. Routine monitoring (ECG, oxygen saturation and noninvasive arterial blood pressure) was performed by taking the patients to the operating room without premedication. Intravenous (iv) pathway was formed by a $20 \mathrm{G}$ intravenous cannula over the nondominant dorsum of the hand, and $0.9 \% \mathrm{NaCl}$ infusion $(6-8$ $\mathrm{ml} \mathrm{kg}^{-1} \mathrm{~h}^{-1}$ ) was started. All the patients were preoxygenated with $100 \%$ oxygen through a face mask for three minutes; then, general anesthesia was induced iv with midazolam $0.02 \mathrm{mg} \mathrm{kg}^{-1}$, propofol $1-3 \mathrm{mg} \mathrm{kg}^{-1}$ and remifentanil $0.25 \mathrm{mcg}$ $\mathrm{kg}^{-1} \mathrm{~min}^{-1}$ at. After the disappearance of the eyelash reflex, $0.3 \mathrm{mg} \mathrm{kg}^{-1}$ rocuronium bromide was administered them as a muscle relaxant. Two minutes after the muscle relaxant agent was administered, patients were intubated with a neuromonitoring tube through GVL or ML by the $4^{\text {th }}$-year anesthesiologist assistant or specialist anesthesiologist. Cormack Lehane score was recorded before intubation. The duration from the insertion of the laryngoscope blade into the mouth until $\mathrm{ETCO}_{2}$ pressure appears on the monitor is determined as 'intubation time' and is recorded. The correct positioning of the neuromonitoring tube was confirmed on the NIM Response 3.0 Nerve monitor (Medtronic Xomed, USA), and the number of the trial when this was achieved was recorded as the 'number of trials.' The cuff of the tube was inflated by a cuff manometer (Covidien-00308 ${ }^{\circledR}$ ) up to $25 \mathrm{~cm} \mathrm{H}_{2} \mathrm{O}$. In the maintenance of anesthesia, desflurane $6 \%$, remifentanil $0.05^{-2} \mathrm{mcg} \mathrm{kg}^{-1} \mathrm{~min}^{-1} \mathrm{O}_{2} 40 \%$ and air $60 \%$ were administered. HR (Heart Rate), fingertip $\mathrm{SpO}_{2}$ (Peripheral Capillary Oxygen Saturation), SBP (Systolic Blood Pressure), DBP (Diastolic Blood Pressure) and MBP (Mean Blood Pressure) scores of the patients were recorded at preinduction, post-induction, post-intubation and three minutes after intubation. Hemodynamic findings were followed up and recorded by the same people who intubated until the end of the operation. HR and MBP were treated with $0.01 \mathrm{mcg} \mathrm{kg}^{-1}$ atropine and $5 \mathrm{mg}$ ephedrine, respectively, when they were $20 \%$ below the baseline. Fingertip $\mathrm{SpO}_{2}$ was not allowed decreasing below $90 \%$. For postoperative analgesia, all patients were administered $10-15 \mathrm{mg} \mathrm{kg}^{-1}$ paracetamol and 1 $\mathrm{mg} \mathrm{kg}^{-1}$ tramadol. 10-40 $\mathrm{mcg} \mathrm{kg}^{-1}$ granisetron was administered to prevent nausea and vomiting 15 minutes before waking. After the anesthesia was terminated and the patient was extubated, complications of the patient (cough and the presence of blood on the intubation tube) were evaluated and recorded by a blinded MD. The duration of anesthesia and surgery were recorded. The patients were transferred to the surgical service after achieving an Aldrete Score of 9 and above in the wake-up unit.

\section{Statistical Analysis}

The sample size was calculated with the $G$ * PowerVersion 3.1.6 program. The effect size $=0.5$ was considered to be the difference between the groups. The alpha significance level was calculated from 175 patients with a power of 0.05 to $95 \%$. We included 180 patients in this study. SPSS 15.0 for Windows was used for statistical analysis. The descriptive statistics were expressed in numbers and percentages for 
categorical variables; and in mean, standard deviation, and minimum and maximum values for numerical variables. Two independent variables were compared with the One Way ANOVA test when the normal distribution condition was met and with the Kruskal-Wallis test if the normal distribution condition was not met. Sub-groups were compared with Tukey test for parametric tests and with the MannWhitney $U$ test for non-parametric tests. The results were interpreted with the Bonferroni correction. The ratios of the categorical variables among the groups were tested by the Chi-Square Analysis. The statistical alpha significance level was set at $p<0.05$.

\section{Results}

One hundred eighty patients were successfully intubated and all of them were evaluated statistically in this study.

Age and BMI (Body Mass Index) were found to be statistically significantly higher in Group $G$ than in Group M ( $p=0.044$ $p=0.027$ ) (Table 1). There was no statistically significant difference between the groups of mallampati scores and Cormack Lehane scores ( $p>0.05)$.

Intubation time was significantly higher in Group $G$ $(35.3 \pm 10.3 \mathrm{sec})$ than Group M $(22.1 \pm 7.7 \mathrm{sec})$ (Table 2).
There was no statistically significant difference between the groups in the number of trials ( $p>0.05$ )

In Group M, HR scores of postintubation and three minutes after intubation were found to be statistically significantly higher than in Group $\mathrm{G}(\mathrm{p}=0.006, \mathrm{p}=0.029)$ (Table 3). There was a statistically significant change detected in HR levels among the groups in the follow-up $(p<0.001)$.

There was a statistically significant change found in SBP levels in all intra-group changes in both groups $(p<0.001)$ (Table 4). However, no statistically significant difference was found among the groups ( $p>0.05$ ).

In Group M, postintubation DBP scores were found to be statistically significantly higher compared to Group G $(p=0.001, p=0.013)$ (Table 5). There was a statistically significant change found in DBP levels in all intra-group changes in both groups in the follow-up $(p<0.001)$.

In Group $M$, postintubation MBP scores were found to be statistically significantly higher compared to Group $G$ $(p=0.011)$. There was a statistically significant change found in MBP levels in all intra-group changes in both groups in the follow-up $(p<0.001)$ (Table 6).

$\mathrm{SpO}_{2}$ values of postinduction, postintubation and three minutes after intubation were found to be statistically sig-

Table 1. Comparison of demographic data, anesthesia and surgical time according to groups $(*: p<0.05)$

\begin{tabular}{|c|c|c|c|}
\hline & \multicolumn{2}{|c|}{ Group } & \multirow[t]{2}{*}{$\mathbf{p}$} \\
\hline & $G(n=90)$ & $M(n=90)$ & \\
\hline Age, Mean \pm SD (Min-Maks) & $46.1 \pm 11.4(22-65)$ & $42.9 \pm 11.2(22-65)$ & $0.044^{*}$ \\
\hline \multicolumn{4}{|l|}{$\operatorname{Sex}(\%)$} \\
\hline Man & $18(18.9)$ & $20(22.5)$ & 0.554 \\
\hline Woman & $73(81.1)$ & $69(77.5)$ & \\
\hline Weight, Mean $\pm S D$ & $74.0 \pm 12.7$ & $70.6 \pm 11.6$ & 0.083 \\
\hline Height $(\mathrm{cm})$, Mean $\pm S D$ & $162.2 \pm 11.8$ & $163.7 \pm 7.7$ & 0.546 \\
\hline $\mathrm{BMI}$, Mean \pm SD & $29.2 \pm 15.0$ & $26.4 \pm 4.3$ & $0.027^{*}$ \\
\hline Mallampati Score, Mean \pm SD & $1.96 \pm 0.79$ & $2.01 \pm 0.73$ & 0.554 \\
\hline Cormack Lehane Score, Mean \pm SD & $1.82 \pm 0.53$ & $1.78 \pm 0.64$ & 0.432 \\
\hline \multicolumn{4}{|l|}{ Operation (\%) } \\
\hline Parathyroid & $25(26.7)$ & $19(21.3)$ & 0.405 \\
\hline Thyroid & $66(73.3)$ & $70(78.7)$ & \\
\hline
\end{tabular}

Table 2. Comparison of the number of trials and intubation time by groups $\left({ }^{*}: p<0.05\right)$

\begin{tabular}{|c|c|c|c|}
\hline & \multicolumn{2}{|c|}{ Group } & \multirow[t]{2}{*}{$\mathbf{p}$} \\
\hline & $\mathbf{G}(n=90)$ & $M(n=90)$ & \\
\hline \multicolumn{4}{|l|}{ Trial Number } \\
\hline Second & $2(2.2)$ & $7(7.9)$ & 0.100 \\
\hline First & $88(97.8)$ & $82(92.1)$ & \\
\hline Intubation Time (Sec), Mean \pm SD & $35.3 \pm 10.3$ & $22.1 \pm 7.7$ & $<0.001 *$ \\
\hline
\end{tabular}


Table 3. Comparison of the Heart Rate (HR) values by groups $(*: p<0.05)$

\begin{tabular}{lccc}
\hline & \multicolumn{2}{c}{ Group } & \\
\cline { 2 - 4 } & $\begin{array}{c}\mathbf{G}(\mathbf{n}=\mathbf{9 0}) \\
\text { Mean } \pm \mathbf{S C}\end{array}$ & $\begin{array}{c}\mathbf{M}(\mathbf{n}=\mathbf{9 0}) \\
\text { Mean } \pm \mathbf{S C}\end{array}$ & $\mathbf{p}$ \\
\hline HRPreinduction (beat/min) & $80.2 \pm 10.7$ & $80.1 \pm 11.5$ & 0.947 \\
Postinduction & $72.3 \pm 11.8$ & $74.8 \pm 9.5$ & 0.119 \\
Postintubation & $85.9 \pm 13.0$ & $91.7 \pm 14.6$ & $\mathbf{0 . 0 0 6 *}$ \\
Postintubation 3. min & $79.3 \pm 12.0$ & $83.2 \pm 11.4$ & $\mathbf{0 . 0 2 9 *}$ \\
p & $<\mathbf{0 . 0 0 1 *}$ & $<\mathbf{0 . 0 0 1 *}$ & \\
\hline
\end{tabular}

Table 4. Comparison of the sistolic Blood Pressure (SBP) values by groups $(*: p<0.05)$

\begin{tabular}{|c|c|c|c|}
\hline & \multicolumn{2}{|c|}{ Group } & \multirow[t]{3}{*}{$\mathbf{p}$} \\
\hline & $G(n=90)$ & $M(n=90)$ & \\
\hline & Mean \pm SC & Mean \pm SC & \\
\hline \multicolumn{4}{|l|}{$\mathrm{SBP}(\mathrm{mmHg})$} \\
\hline Preinduction & $149.6 \pm 20.7$ & $144.5 \pm 21.9$ & 0.110 \\
\hline Postinduction & $105.5 \pm 16.6$ & $109.8 \pm 18.0$ & 0.103 \\
\hline Postintubation & $131.4 \pm 22.1$ & $135.0 \pm 26.4$ & 0.321 \\
\hline Postintubation 3. min & $111.9 \pm 18.3$ & $114.1 \pm 19.3$ & 0.443 \\
\hline $\mathrm{p}$ & $<0.001^{*}$ & $<0.001^{*}$ & \\
\hline
\end{tabular}

Table 5. Comparison of the Diastolic Blood Pressure (DBP) values by groups ( $\left.{ }^{*}: p<0,05\right)$

\begin{tabular}{|c|c|c|c|}
\hline & \multicolumn{2}{|c|}{ Group } & \multirow[t]{3}{*}{$\mathbf{p}$} \\
\hline & $G(n=90)$ & $M(n=90)$ & \\
\hline & Mean $\pm S C$ & Mean \pm SC & \\
\hline \multicolumn{4}{|l|}{$\mathrm{DBP}(\mathrm{mmHg})$} \\
\hline Preinduction & $81.0 \pm 10.7$ & $82.8 \pm 11.8$ & 0.310 \\
\hline Postinduction & $59.3 \pm 12.1$ & $66.1 \pm 14.5$ & 0.001 \\
\hline Postintubation & $77.8 \pm 15.8$ & $84.6 \pm 19.9$ & 0.013 \\
\hline Postintubation 3. min & $66.4 \pm 14.1$ & $69.9 \pm 13.2$ & 0.089 \\
\hline $\mathrm{p}$ & $<0.001^{*}$ & $<0.001^{*}$ & \\
\hline
\end{tabular}

Table 6. Comparison of the Mean Blood Pressure (MBP) values by groups $(*: p<0,05)$

\begin{tabular}{|c|c|c|c|}
\hline & \multicolumn{2}{|c|}{ Group } & \multirow[t]{3}{*}{$\mathbf{p}$} \\
\hline & $G(n=90)$ & $M(n=90)$ & \\
\hline & Mean \pm SC & Mean \pm SC & \\
\hline \multicolumn{4}{|l|}{$\mathrm{MBP}(\mathrm{mmHg})$} \\
\hline Preinduction & $104.8 \pm 15.4$ & $104.0 \pm 14.3$ & 0.772 \\
\hline Postinduction & $96.9 \pm 16.9$ & $101.8 \pm 21.4$ & 0.085 \\
\hline Postintubation & $75.2 \pm 12.5$ & $80.2 \pm 13.3$ & $0.011^{*}$ \\
\hline Postintubation 3. min & $82.0 \pm 14.7$ & $83.5 \pm 16.6$ & 0.528 \\
\hline $\mathrm{p}$ & $<0.001^{*}$ & $<0.001^{*}$ & \\
\hline
\end{tabular}

nificantly higher compared to preinduction in intra-group changes in both groups $(p<0.001)$ (Table 7$)$. However, no difference was found among the groups $(p>0.05)$.
No statistically significant change was found in intra-group complications (blood on the intubation tube and coughing after extubation) ( $p=0.828, p=0.805)$ (Fig. 1). 
Table 7. Comparison of Peripheral Capillary Oxygen Saturation $\left(\mathrm{SpO}_{2}\right)$ values by groups ( $(*: p<0.05)$

\begin{tabular}{|c|c|c|c|}
\hline & \multicolumn{2}{|c|}{ Group } & \multirow[t]{3}{*}{$\mathbf{p}$} \\
\hline & $G(n=90)$ & $M(n=90)$ & \\
\hline & Mean \pm SD & Mean \pm SD & \\
\hline \multicolumn{4}{|l|}{$\mathrm{SpO}_{2}$} \\
\hline Preinduction & $97.5 \pm 1.6$ & $97.4 \pm 1.7$ & 0.733 \\
\hline Postinduction & $98.2 \pm 9.6$ & $99.3 \pm 0.8$ & 0.894 \\
\hline Postintubation & $99.2 \pm 1.1$ & $99.2 \pm 1.3$ & 0.564 \\
\hline Postintubation 3. min & $99.2 \pm 1.1$ & $99.4 \pm 0.8$ & 0.781 \\
\hline $\mathrm{p}$ & $<0.001^{*}$ & $<0.001^{*}$ & \\
\hline
\end{tabular}

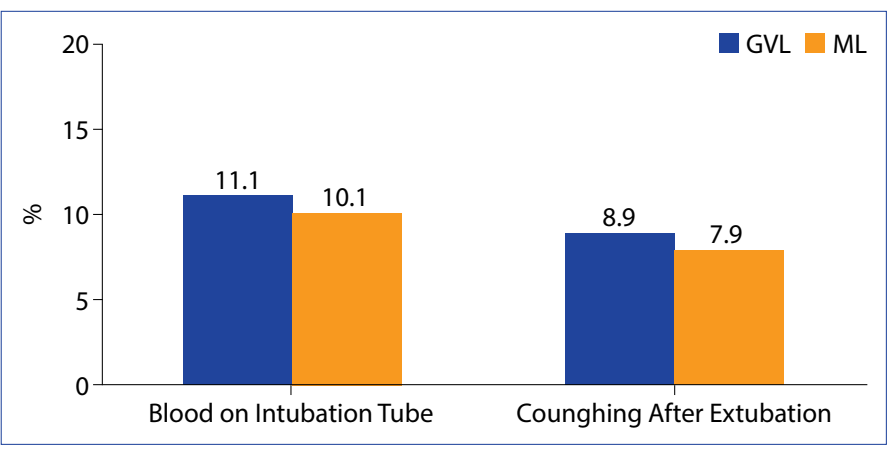

Figure 1. Distribution of Complications by Groups.

\section{Discussion}

GlideScope has an angle of 60 degrees in the midline and does not need to align the oral, pharyngeal and laryngeal axis during intubation. ${ }^{[7]}$ Thus, it may cause lower hemodynamic changes during laryngoscopy and stimulate oropharynx at lower rates. Despite the slight change in hemodynamic parameters in both groups, in the group intubated with GVL in our study, HR, DBP and MBP scores were significantly lower than the $M L$ group after intubation. In the other studies that examined the effects of GVL and $M L$ on the hemodynamic response, patients' hemodynamic data after intubation varied, but no statistically significant differences were found between the two methods. ${ }^{[7,8]}$ When Misirlioglu et al. ${ }^{[9]}$ compared the effects of the ML and GVL to hemodynamic response in 100 patients, aged 18-65, in ASA 1-2 group, who underwent otorhinolaryngology operation under elective conditions, the hemodynamic response was found to be significantly higher in patients intubated with $M L$. As a result of this study, GVL was found to be safer in cases where hemodynamic stability was a vital necessity. It was found that hemodynamic parameters were better maintained with GVL in pregnant women. ${ }^{[10]}$ In 60 uncontrolled hypertension patients, where the intubation-related hemodynamic changes of GVL and ML were compared, hemodynamic changes after intubation were fewer in the GVL group compared to the ML group. ${ }^{[1]}$ Kanotra et al., ${ }^{[12]}$ who investigated the performance of GVL in patients with thyroid surgery with the neuromonitoring tube, concluded in their study on 250 patients that GVL was an excellent instrument for ensuring the correct positioning of the neuromonitoring tube. They concluded that the intubation technique allowed both the surgeon and the anesthesiologist to participate in the intubation process and to confirm the correct positioning of the tube, while at the same time improved visibility allowed soft intubation.

In their study that examined the relationship between successful intubation with GVL with experience and involved interns who have made more than 50 successful intubation procedures with GVL and $\mathrm{ML}$, Agil et al. ${ }^{[13]}$ compared the routine use, intubation conditions under elective conditions, success rate and intubation easiness of both devices. Glottic view was better in the GVL group and intubation time and easiness were found to be in favour of the GVL group. In another study on the experience of the intubator, the incidence of sore throat after intubation was found to be higher in certified anesthesia nurses, compared to clinical anesthesiologists with three years' experience. ${ }^{[14]}$ In our study, all patients were intubated by a $4^{\text {th }}$-year anesthesiologist assistant or specialist anesthesiologist. Thus, we tried to prevent the statistical data variation by minimizing the complications and delays due to inexperience related to the use of GVL.

Glidescope is often the first choice laryngoscopy method in challenging airways. However, it is controversial that it presents a good larynx image in normal airways. ${ }^{[15]}$ The GVL and ML were compared in 60 patients in the ASA 1-2 group with normal airway operated under elective conditions and the laryngoscopic view was obtained better in GVL and the time required for successful intubation was the same in both methods. Thus, it was concluded that GVL might be the first preferred vehicle in normal airways. ${ }^{[15]}$ In another study comparing intubation times of GVL and $\mathrm{ML}$, the use of GVL to facilitate intubation resulted in a better glottic view, but endotracheal intubation lasted longer. ${ }^{[7]}$ 
Pournajafian et al ${ }^{[8]}$ compared the GVL and ML in 95 patients in ASA 1-2 group who were operated under elective conditions and suggested that if the time required for intubation was reduced in the group intubated with glideslope, the benefit of GVL might become more evident. GVL improves glottic vision in patients with normal airway and allows easy intubation. ${ }^{[7,8,15]}$ The researchers wanted to compare this advantage of GVL with direct laryngoscopy in pregnant and obese patients. It was found that intubation times were similar when GVL and ML were compared in patients undergoing caesarean section under elective conditions. ${ }^{[9]}$ In their study on 100 morbid obese patients with body mass index $>35$, Andersen et al. ${ }^{[16]}$ compared GVL and $\mathrm{ML}$ concerning intubation time. The intubation period was longer in the GVL, but since the laryngoscopic view was better and the patients were not hypoxemic during intubation, they found the increase in intubation time to be clinically insignificant. We have used the opaque closed envelope system in randomization, but BMI and age were found to be statistically higher in the GVL intubated group among our patients. However, the average age of patients in the same decade and weight average in the overweight class. Therefore, we do not think that this situation causes a change in statistical data. We confirm that the intubation time was long in the group intubated with GVL. This might have resulted from the restricted tube movement due to the large size of the GVL blade and extensive coverage in the mouth. However, the long duration did not cause any decrease in fingertip $\mathrm{SpO}_{2}$.

In our study, we gave patients $0.3 \mathrm{mg}$ of rocuronium bromide (half of the standard dose). Studies on this topic indicate that this dose is optimal for intubation. ${ }^{[5,6]}$ Han et al. ${ }^{[5]}$ used the TOF-Watch SX accelerometer in their study. In our study, we could not use the TOF device because we did not have. We started remifentanil infusion to the patients to facilitate intubation condition at induction, and it provided us satisfactorily.

The forces applied during laryngoscopy and intubation may damage the oropharyngeal soft tissues. No difference was found between the two groups concerning mucosal damage in our study as well. Parasa et al. ${ }^{[7]}$ documented higher mucosal damage in the GVL group than the ML group in the study that involved 60 patients in the ASA 1-2 group who underwent surgery under elective conditions. When classic laryngoscopy failed, and GVL was used as recovery laryngoscopy, anesthesiologists found that patients had a sore throat after the procedure. However, to ascertain whether sore throat results from multiple laryngoscopic interventions or direct use of GVL, 151 patients in the ASA-13 group who were operated under elective conditions were studied. They did not find a significant difference in the incidence of sore throat in patients intubated with GVL or ML/Miller Blade. ${ }^{[14]}$ Carasatti et al. ${ }^{[17]}$ compared direct laryngoscopy and video laryngoscopy by measuring the forces applied during maneuvers to provide glottis appearance and tracheal intubation. In an in vivo study conducted on 30 patients in ASA $1-2$ group with BMI $18-30 \mathrm{~kg} / \mathrm{m}^{2}$, who were not expected to have difficult intubation, while the forces were mainly concentrated on the tip when using $\mathrm{ML}$, no concentration was observed in GVL due to forces in a specific region. Thus, minimal force applied for glottis visualization and forces applied during intubation were found to be lower than GVL and ML. In another study conducted by the same author, the damage to soft tissue during intubation with $\mathrm{ML}$ and GVL was compared on mannequins with normal and difficult airways. All participants applied a lower mean force on GVL than ML in normal and difficult airways. ${ }^{[18]}$ In the study where mucosal damage caused by GVL and ML was examined in 70 patients who underwent caesarian operation under elective conditions, no difference was detected concerning soar throat between two groups. ${ }^{[9]}$

\section{Conclusion}

Despite its long intubation time, GVL has a slight effect than $\mathrm{ML}$ on hemodynamism in the thyroid or parathyroid cases that intubated with low dose muscle relaxants for neuromonitoring. Thus, we believe that GVL may be the first choice laryngoscopy method in thyroid and parathyroid cases that using neuromonitorization.

\section{Main Points}

- Glidescope video laryngoscope (GVL) and Macintosh laryngoscope (ML) are two separate intubation techniques, and during intubation, patients may experience increased blood pressure, tachycardia and mucosal damage.

- GVL facilitates intubation, especially in the difficult airway due to its improved visibility but requires experience and concerns about mucosal damage.

- We compared GVL and ML because we were curious about the hemodynamic response, intubation time and mucosal damage of patients during different intubation techniques due to the use of half of the standard dose muscle relaxant in thyroid and parathyroid cases with neuromonitorization.

- In our study, the heart rate, diastolic blood pressure and mean arterial pressure after intubation were statistically lower in the group intubated with GVL compared to those intubated with $M L(p=0.006, p=0.013, p=0.011)$. The intubation time was higher in the GVL group, but 
this did not lead to a hypoxic condition $(35.3 \pm 10.3$, $22.1 \pm 7.7 \mathrm{sec}$ ). There was no statistical difference between the two groups concerning mucosal damage

- Thus, we think that GVL may be the first choice for intubation due to its fewer effects on hemodynamic response and not increasing mucosal injury in cases of thyroid and parathyroid using low dose muscle relaxants.

\section{Disclosures}

Ethics Committee Approval: The Ethics Committee of Istanbul Hamidiye Şişli Etfal Training and Research Hospital provided the ethics committee approval for this study (07.03.2017/753).

Peer-review: Externally peer-reviewed.

Conflict of Interest: None declared.

Authorship Contributions: Concept - M.G., A.S.C.; Design - M.G.; Supervision - A.S.C.; Materials - M.G., M.U.; Data collection \&/or processing - M.G., M.U.; Analysis and/or interpretation - M.G., A.S.C.; Literature search - M.G.; Writing - M.G., A.S.C., M.U.; Critical review - M.U.

\section{References}

1. Kayhan Z. Klinik Anestezi. 3rd ed. İstanbul: Logos Publishing; 2004. p. 243-73.

2. Channa AB. Video laryngoscopes. Saudi J Anaesth 2011;5:357-9.

3. İsgör A. Tiroid Hastalıkları ve Cerrahisi. 1st ed. Istanbul: Avrupa Tip; 2000. p. 515-93.

4. Eisele DW. Intraoperative electrophysiologic monitoring of the recurrent laryngeal nerve. Laryngoscope 1996;106:443-49. [CrossRef]

5. Han YD, Liang F, Chen P. Dosage effect of rocuronium on intraoperative neuromonitoring in patients undergoing thyroid surgery. Cell Biochem Biophys 2015;71:143-6. [CrossRef]

6. Lu IC, Tsai CJ, Wu CW, Cheng KI, Wang FY, Tseng KY, et al. A comparative study between 1 and 2 effective doses of rocuronium for intraoperative neuromonitoring during thyroid surgery. Surgery 2011;149:543-8. [CrossRef]

7. Parasa M, Yallapragada SV, Vemuri NN, Shaik MS. Comparison of GlideScope video laryngoscope with Macintosh laryngoscope in adult patients undergoing elective surgical procedures. Anesth Essays Res 2016;10:245-9. [CrossRef]

8. Pournajafian AR, Ghodraty MR, Faiz SH, Rahimzadeh P, Goodar- zynejad H, Dogmehchi E. Comparing GlideScope Video Laryngoscope and Macintosh Laryngoscope Regarding Hemodynamic Responses During Orotracheal Intubation: A Randomized Controlled Trial. Iran Red Crescent Med J 2014;16:e12334. [CrossRef]

9. Misirlioglu G, Sen O. Comparison of GlideScope video laryngoscopy and Macintosh laryngoscope in ear-nose and throat surgery. Ir J Med Sci 2016;185:729-33. [CrossRef]

10. Amini S, Shakib M. Hemodynamic changes following endotracheal intubation in patients undergoing cesarean section with general anesthesia: application of glidescope ${ }^{\circledR}$ videolaryngoscope versus direct laryngoscope. Anesth Pain Med 2015;5:e21836.

11. Dashti M, Amini S, Azarfarin R, Totonchi Z, Hatami M. Hemodynamic changes following endotracheal intubation with glidescope $\left.^{(}\right)$video-laryngoscope in patients with untreated hypertension. Res Cardiovasc Med 2014;3:e17598. [CrossRef]

12. Kanotra SP, Kuriloff DB, Lesser J, Rest-Flarer F. GlideScope-assisted nerve integrity monitoring tube placement for intra-operative recurrent laryngeal nerve monitoring. J Laryngol Otol 2012;126:1271-3. [CrossRef]

13. Aqil M, Khan MU, Hussain A, Khokhar RS, Mansoor S, Alzahrani T. Routine Use of Glidescope and Macintosh Laryngoscope by Trainee Anesthetists. J Coll Physicians Surg Pak 2016;26:245-9.

14. Cirilla DJ 2nd, Ngo J, Vaisman V, Daly C, Ata A, Sandison M, et al. Does the incidence of sore throat postoperatively increase with the use of a traditional intubation blade or the GlideScope? J Clin Anesth 2015;27:646-51. [CrossRef]

15. Choi GS, Lee EH, Lim CS, Yoon SH. A comparative study on the usefulness of the Glidescope or Macintosh laryngoscope when intubating normal airways. Korean J Anesthesiol 2011;60:339-43.

16. Andersen LH, Rovsing L, Olsen KS. GlideScope videolaryngoscope vs. Macintosh direct laryngoscope for intubation of morbidly obese patients: a randomized trial. Acta Anaesthesiol Scand 2011;55:1090-7. [CrossRef]

17. Carassiti M, Biselli V, Cecchini S, Zanzonico R, Schena E, Silvestri S, et al. Force and pressure distribution using Macintosh and GlideScope laryngoscopes in normal airway: an in vivo study. Minerva Anestesiol 2013;79:515-24.

18. Carassiti M, Zanzonico R, Cecchini S, Silvestri S, Cataldo R, Agrò FE. Force and pressure distribution using Macintosh and GlideScope laryngoscopes in normal and difficult airways: a manikin study. $\mathrm{Br}$ J Anaesth 2012;108:146-51. [CrossRef] 